of learning and science as "are now or may be hereafter taught in the English universities", but subject to "the fundamental and immutable rule and condition" that the professors, officers, students, etc., shall not be required to submit to any religious test whatsoever. Owens's estate realized $£ 168,02510 s .5 d$, and the residue which came to the College was $£ 96,6544 s$. 6d. The College was opened in 1851 in William Cobden's old house, and new buildings were erected in 1870-73. Frankland was the first professor of chemistry, and in 1857 he was succeeded by Roscoe, under whom worked many men afterwards famous. The engineering department was opened in 1868 with Osborne Reynolds as professor of civil and mechanical engineering. "Owens," says Mr. Redford, in the article referred to, "was a plain man with no aspirations to greatness, who builded better than he knew.'?

\section{Memorial to John Dalton}

Two years ago, on the pecasion of the centenary of the death of Johr Dajworn (see Nature, 154, 103; 1944), the Socie Friends arranged to erect a memorial stofe to his memory in the quiet graveyard at Pardghaw Hall close by his birthplace, Eaglesfield, near 80 dermouth, Cumberland. Dalton was educated lat the Quaker School at Eaglesfield and was a tedefer there before he removed first to Kendal and then in 1793 to Manchester, where he spent the remainder of his life. At his death on July 27, 1844, he was buried in the public cemetery at Ardwick, but it is considered by some that he would have preferred to be buried in his native county. Owing to the War the plan made in 1944 for a memorial stone had to be postponed, but is now to be carried out. The stone will bear his name, places and dates of birth and death, and the epitaph "Not for an age but for all time: This to his memory".

\section{Mineral Development in Great Britain}

The Minister of Fuel and Power has appointed a committere, to be known as the Mineral Development Comndttee, with the following terms of reference : "ID inquire into the resources of minerals in , the Onited Kingdom, excepting coal, oil, bedded ironstone, and substances of widespread occurrence; to consider possibilities and means of their eo-ordinated, orderly, and economic development in the national interest, and to make recommendations in regard thereto".

The Committee is constituted as follows: Lord Westwood (Chairman); Mr. T. Balogh (Institute of Statistics, University of Oxford); Mr. A. R. Davies (partner in the firm of T. C. Horabin and Partners, industrial consultants); Prof. W. R. Jones (Imperial College of Science and Technology ; adviser to Board of Trade (China Clay); chairman, China Clay Working Party); Mr. L. C. Hill (technical adviser to the board of directors of Rio Tinto, Ltd.); Prof. A. O, Rankine (chief physicist, Anglo-Iranian Oil Co., Ltd.) ; Prof. J. A. S. Ritson (professor of mining, Royal School of Mines; deputy chairman of the Coal Commission); Mr. Stanley Robson (director of Imperial Smelting Corporation, Ltd.) ; Mr. Tom Steele, M.P. ; Captain Peter Thorneycroft, M.P.; and Mr. R. E. Yeabsley (partner in the firm of Hill, Vellacott \& Co., chartered accountants). The secretary of the Committee is Mr. W. C. C. Rose, to whom all communications should be addressed at the Ministry of Fuel and Power, 40 Upper Brook Street, London, W.1.

\section{Scientific Posts in the Development of Atomic Energy}

Accordrng to the Daily Mail of August 3, Mr. L. J. F. Brimble, joint editor of Nature, attacked "Secrecy over the appointment of scientists to posts in the development of atomic energy", at a gathering of "scientists at Wadham College, Oxford". This statement is so inaccurate as to convey the opposite of that which $\mathrm{Mr}$. Brimble actually did say. He. was addressing the summer school of the British Social Hygiene Council on "Science and Social Progress". In dealing with atomic energy, Mr. Brimble pleaded that public (especially lay) opinion should be based on more accurate and fuller knowledge. Ho gave a brief history of atomic research in an attempt to show that no one country could claim all the credit, and emphasized the important pioneer work of Dalton in Manchester followed later by the crucial researches under Rutherford at Cambridge. This, he claimed, should be more widely known, for it might surprise some if they knew how widespread among the lay public was the belief that all atomic research had so far been practically confined to the United States. As regards the appointment of physicists to posts dealing with atomic research, Mr. Brimble neither said nor implied anything. In fact it should here be stated that in the opinion of the Editors of Nature, such posts as exist in Britain are held by the most suitable and competent men of science, and, so far as they are aware, there has been no "secrecy" in appointing them. Mr. Brimble did, however, direct attention to the hasty decisions being made in appointing personnel to certain scientific and educational bodies-decisions which seem to be made by a few without consulting other authorities-and often not followed by any published announcement of such appointments. Those bodies which Mr. Brimble had in mind are far removed from atomic energy, or indeed any other kind of scientific researeh.

$$
1012
$$

\section{Pharmaceutical Products and their Manufacture}

Mr. B. A. Buri, in his address as chairman to the British Phar ofytcal Conference meeting in London on July/ 6 , Deviefed the various fields of develop$m$ fnt in pharmaceutical practice which have occurred difyig the past ten or fifteen years. A good deal of abtention has been devoted to methods of analytical control, particularly the extension of physical methods, such as spectroscopic, adsorption, fluorimetric, X-ray and the selenium eell. The technique of microanalysis had been developed so that routine examinations can be carried through with a considerable degree of both speed and accuracy. Adsorption has been applied in the development of chromatography. The range of synthetic chemical compounds having medicinal properties has been widely extended and, in addition to the synthesis of naturally occurring substances such as the vitamins and the development of fermentation, and biological processes, whole series of new compounds possessing marked physiological activity have been prepared. The search for true chemotherapeutic agents has proceeded with increased vigour and with considerable success, notably in the case of penicillin.

Many new developments have occurred in the basic processes underlying manufacturing processes. Thus with vacuum evaporators, the design has tended to emphasize the advantage of rapid circulation of the liquid with a consequent diminution in 
the risk of damaging the product due to local overheating. Electronies have brought a contribution in the evaporation of solutions of heat-sensitive materials such as penicillin by means of radio-frequency dielectric heating, in which the heat is generated directly in the liquid concerned. No temperature gradients are present as is the case when an external source of heat is used and heat transfer has to take place through the wall of the container. Radiofrequency heating is not an economic proposition for heating stable liquids, but may prevent serious losses of activity in heat-sensitive ones. Considerable progress had been made in drying; and spraydrying, flash-drying and drum-drying have been developed with considerable success. The so-called freeze-drying has proved extremely valuable in the final stages of drying penicillin. Much attention has been given to the materials used for the construction of plant and storage vessels. Stainless steel has proved extremely useful, but experience has discovered some important defects in its characteristics which require careful attention; thus when it is welded, seeping may develop through the metal on a line parallel to the weld. Research has shown that if stainless steel is kept for a short time at a temperature of about $650^{\circ} \mathrm{C}$., changes in crystalline structure take place which render the material susceptible to cracking on the application of even slight mechanical stress and to corrosion by liquids which will not attack normal stainless steel. Great care must therefore be taken that it is not subjected to conditions which will take from it the right still to be regarded as stainless steel. bf

\section{Institution of Electrical Engineers}

The May issue of Beflournal of the Institution of Electrical Engineers Mntains a foreword with the heading "Sevent/IVe Years", describing the manner in which theigst founder members of the Institution met in May 1871 , "To consider the expediency of H rm Society of Telegraph Engineers, having for it. objoct the general advancement of electrical and telegraphic science and more particularly for facilitating the exchange of information and ideas among its members". At the outset the Society devoted most of its attention to electrical telegraphy, but in 1879 its scope was enlarged and its title changed to "The Society of Telegraph Engineers and Electricians", in order to provide for the interest aroused by the commercial application of electric lighting. With the rapid development of electrical engineering the title was altered again, to "The Institution of Electrical Engineers", in January 1889, when Sir William Thomson, later Lord Kelvin, delivered the first presidential address to the new body, which was granted a royal charter of incorporation in 1921 . During the seventy-five years of its existence, the Institution has become an important and influential body with nearly 13,500 corporate members and more than 15,000 members of other grades on its register. With the aid of the specialized sections formed in recent years to deal with the fields of installations, measurements, radio and transmission, the Institution caters for this vast membership by pursuing a steady, but vigorous, policy of promoting the general advancement of electrical science and engineering and their applications.

The following have been elected officers of the Institution of Electrical Engineers for 1946-47: President: V. Z. de Ferranti; Vice-Presidents : J. Hacking, T. Graeme N. Haldane, Prof. E. B.
Moullin; Honorary Treasurer: E. Leete; New Members of Council: Dr. T. E. Allibone, D. B. Hoseason, Col. B. H. Leeson, H. Nimmo (members); C. S. Briggs, Dr. F. C. Williams (associate members); . G. Wansbrough (companion).

\section{Joints and Sealing nds for Pressure Cablè}

A PAPER by Dpr I. G. Brazier, read in London before the Institat on of Electrical Engineers, discusses the genefer of inciples involved in the design of joints gudseafing ends for pressure-cable installations. Dpsigs standards based on experimeńtal results are g won, and practical methods of construction are described. An account is also given of the gas-control accessories of a pressure cable, including leak location methods. Special attention is given to the problem of voltage surges in relation to joints and sealing ends, and it is shown that the voltage surges specified as representing service conditions are now a critical factor determining the amount of insulation. The relative economics of providing for the voltage surges by additional insulation or alternatively by surge diverters are examined.

\section{A Scottish Statistical Research Bureau}

A Scottish Sphitstical Research Bureau has been set up infolnourgh, following discussions which have tak place between the four Scottish universipips ofd the Faculty of Actuaries. Its object is to plat statistical experience and advice at the disposal of research workers in possession of statistical material. The Bureau functions through a Central Committee, of which the first chairman is Mr. J. G. Kyd, Registrar-General for Scotland and lately president of the Faculty of Actuaries. The secretary is Mr. E. Waugh, Faculty of Actuaries, $23 \mathrm{St}$. Andrew Square, Edinburgh.

Prehistory in South Africa

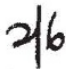

THE first number of a new series of bulletins of the South Africapt Archæological Society, Cape Town, will be of gentotinterest to all prehistorians. These bulletin f will not be confined exclusively to South African Ctudies, but will embrace accounts of research d f cin other areas. The first bulletin, for example, not only describes a preliminary survey of work in South Africa and discusses colour in prehistoric rock paintings, but also includes an account by J. d'A. Waechter of an archæological excavation in the Middle East, and a brief note on the mesolithic cultures of Britain. These bulletins will help to link up more closely South African archæologists, and also act as a convenient medium between them and their colleagues in other countries.

A Blue Moon

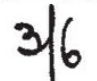

Sky and Telescope for March has an article by J. Hugh Pruett "f the title "Once in a Blue Moon", in which thene is a discussion of the origin of the expresfon ${ }^{\text {t }}$ The chief interest in the article consists, nets 11 me in referring to the theories regarding the orifin of 'a blue moon', as in providing irrefutable evldend from several sources that a blue moon has actually been observed on different occasions. The author of the article states that he saw the phenomenon himself on July 28, 1944. The moon was at the first-quarter phase that day and was thinly veiled by a small patch of high cirrus clouds which were tinted a beautiful orange-red by the sun just below the horizon. It was thought that the lunar blue might be the effect of contrast with the red of the clouds, but this view was shown to be incorrect 